\title{
Characterization and Expression Analysis of Peroxidases and Glucan Synthase Like Genes in Cucumis melo L.
}

\author{
Jewel Howlader ${ }^{\dagger 1}$, Kanij Rukshana Sumi ${ }^{\dagger 2}$, Hoy-Taek Kim ${ }^{\dagger 1}$, Arif Hasan Khan Robin ${ }^{1}$, Jong-In Park ${ }^{1}$, \\ Mi-Young Chung ${ }^{3}$, Ill-Sup Nou ${ }^{1 *}$ \\ ${ }^{1}$ Department of Horticulture, Sunchon National University, Suncheon 57922, Korea \\ ${ }^{2}$ Department of Fisheries Science, Chonnam National University, Yeosu 59626, Korea \\ ${ }^{3}$ Department of Agricultural Education, Sunchon National University, Suncheon 57922, Korea
}

\begin{abstract}
Powdery mildew (PM) is a severe fungal disease for melon cultivation worldwide. Stress resistance related genes could be important tools to address this problem. In this study, we retrieved defense related peroxidase and glucan synthase genes from Melon Genome Database 'Melonomics'. Thereafter, we analyzed the genes in silico. We conducted protein blast in the NCBI database and found a high degree of homology among them. Based on the highest protein homology we named two isoforms of Cucumis melo peroxidase 2-like genes (CmPrx2-1 and CmPrx2-2) and one glucan synthase1-like gene (CmGLS1). In reverse transcriptionpolymerase chain reaction (PCR), all 3 genes showed organ specific expression in a C. melo line, SCNU1154. Real-time quantitative PCR expression of these 3 genes was conducted in the infected leaf samples by PM fungus Podosphaera xanthii and also treated leaf samples by exogenous phytohormones (salicylic acid and methyl jasmonate). The CmPrx2-2 gene was up-regulated in response to all seven races of PM fungus whereas up-regulation or down-regulation of CmPrx2-1 gene was race-specific. The CmGLS1 gene was down-regulated in response to all races except one race. The CmPrx2-1, CmPrx2-2, and CmGLS1 genes were up-regulated under both salicylic acid and methyl jasmonate treatments but their level of expression was higher in salicylic acid treated plants compared to methyl jasmonate. Therefore, we speculate that defense response of the three tested genes is largely mediated by the salicylic acid signaling pathway under PM infection. Taken together, the data presented herein may be useful resources in the development of PM stress resistant in C. melo L.
\end{abstract}

Keywords Melon, Peroxidase, Glucan synthase, Phytohormones, Powdery mildew

\section{INTRODUCTION}

Powdery mildew (PM) disease is severe threat for melon (Cucumis melo L.) cultivation around the world. PM fungus reduces the quantity as well as the quality of cucurbit crop yields (Jarvis et al. 2002). Although in Europe, two severe PM causal agents namely Podosphaera xanthii and Golovinomyces cichoracearum have been reported (Epinat et al. 1993; Kř́stková et al. 2004) but many research showed that $P$. xanthii alone is the major responsible causal agent for PM diseases for melon in many countries (Sowell 1982; Cohen et al. 1984; McCreight et al. 1987; Hosoya et al. 1999; 2000). Application of fungicide is the common control strategy for PM disease in cucurbit crop production (Hewitt 1998). Due to frequent chemical use some PM fungi have gradually evolved their resistance to fungicides (Hollomon and Wheeler 2002). Therefore, development of PM-resistant cultivar is necessary to control this disease (Perchepied et al. 2005).

The biotrophic PM fungi are generally regulated by plant defense signaling pathway like salicylic acid (SA) (Glazebrook 2005; Pieterse et al. 2009) and jasmonate (Glazebrook 2005). This signaling molecules subsequently activate wide range of defense responses such as hypersensitive response (HR); phenylalanine ammonium lyase; cell wall reinforcing materials; and generation of

Received April 20, 2016; Revised May 23, 2016; Accepted May 24, 2016; Published May 31, 2016

*Corresponding author Ill-Sup Nou, nis@sunchon.ac.kr, Tel: +82-61-750-3249, Fax: +82-61-750-3208

${ }^{\dagger}$ These authors contributed equally to this work. 
different antimicrobial products like pathogenesis-related (PR) proteins and phytoalexins resulting in incompatible plant-microbes interaction and hence plant resistance (Veronese et al. 2003; Glazebrook 2005; Pieterse et al. 2009). Furthermore, plant resistance responses to pathogens challenge results from a series of inter-related stages (Dangl and Jones 2001; Veronese et al. 2003). Recognition of pathogen by the host plant is the initial step that often consist of interaction between resistant $(\mathrm{R})$ genes in the host plant and corresponding pathogen avirulence (Avr) genes that encode specific elicitors (Glazebrook 1999; Schulze-Lefert and Vogel 2000).

Peroxidase gene, linked to generate HR and cell wall reinforcement, was induced by phytohormones such as SA and methyl jasmonate (MeJA) (Durrant and Dong 2004; van Loon et al. 2006; Pieterse et al. 2009). Despite high sequence homology (from $28 \%$ to $100 \%$ ) between two peroxidase proteins, there is significant difference observed in their functions such as lignification, suberisation, auxin catabolism, cross-linking of cell wall proteins, defense against pathogen attack, salt tolerance and oxidative stress (Penel et al. 1992; Hiraga et al. 2001). Callose, a $(1,3)-\beta$-glucan polymer, functions in many aspects of plant growth and development (Stone and Clarke 1992). Plant produces callose under a range of biotic and abiotic stresses including wounding, desiccation, metal toxicity, and microbial attack (Stone and Clarke 1992; Ellinger et al. 2013). However, previous reports showed that pathogen-induced callose could be involved negatively to regulate the SA signaling pathway of plants. In Arabidopsis, callose lacked powdery mildew resistant 4 (pmr4) mutant enhanced the SA signaling and increased resistance to pathogen (Nishimura et al. 2003).

PM disease development in melon cultivars varied in response to different races of $P$. xanthii (Bardin et al. 1999). Moreover, a race shift was recorded during the prolonged production period (Sowell 1982; Thomas et al. 1984; Hosoya et al. 1999; 2000). Previous reports showed that peroxidase gene $(P R 9)$ in melon revealed defense response role on induced systemic resistance upon PM fungus inoculation (García-Gutiérrez, 2013). However, Glucan Synthase like-5 (GSL5)/Powdery Mildew Resistant 4 (PMR4)/Callose Synthase 12 (CalS12) generates callose as a defense response upon pathogen challenge to plants. Conversely, due to loss of function mutant of gsl5/pmr4/ cals 12 was unable to generate callose at papillae (Jacobs et al. 2003; Nishimura et al. 2003; Dong et al. 2008). In addition, it is speculated that plant defense response is augmented through secondary defense signaling pathway (Vogel and Somerville 2000). However, there is no interaction information among different races of PM fungus and defense related peroxidase gene as well as glucan synthase genes in melon. Therefore, we planned this study to observe the expression pattern of defense related peroxidase and glucan synthase like genes against different races of PM fungus $P$. xanthii, and under exogenous applications of SA and MeJA in C. melo SCNU1154 line. Moreover, this study will be helpful for future functional characterization of these genes in the development of stress resistant C. melo $\mathrm{L}$.

\section{MATERIALS AND METHODS}

\section{In silico analysis of peroxidase and glucan synthase-like genes}

We collected peroxidase gene (AY373372; GarcíaGutiérrez et al. 2013) and Arabidopsis Powdery Mildew Resistant 4 (PMR4) gene encoding callose synthase (protein AEE82336.1; Huibers et al. 2013) from the literature. Then we blasted these two gene sequences in the Melon Genome Database 'Melonomics' (https://melonomics.net/) and retrieved two peroxidases (Prx) and one glucan synthase $(G L S)$-like genes. Protein homology analysis was done by the Basic Local Alignment Search Tool (BLAST) (http://www.ncbi.nlm.nih.gov/BLAST/) from the National Center for Biotechnology Information (NCBI) database (http://www.ncbi.nlm.nih.gov/gene/) (Table 1). Based on the highest protein homology, the retrieved two peroxidase and one glucan synthase-like genes were named as $C$. melo peroxidase 2-like isoforms 1 (CmPrx2-1), C. melo peroxidase 2-like isoforms $2(\mathrm{CmPrx} 2-2)$, and $C$. melo glucan synthase 1-like (CmGLS1) (Table 1). The primary structures of the genes were studied using ProtParam software (http://expasy.org/tools/protparam.html). Webbased software 'SMART' from European Molecular 
Table 1. Protein homology analysis of CmPrx2-1, CmPrx2-2, and CmGLS1 genes of Cucumis melo (analyzed using BLAST from NCBI, http://www.ncbi.nlm.nih.gov/BLAST/).

\begin{tabular}{|c|c|c|c|c|c|c|}
\hline Gene name & $\begin{array}{l}\text { Top matched } \\
\text { clones }\end{array}$ & Name of protein & $\begin{array}{l}\text { Identity } \\
(\%)\end{array}$ & E-value & $\begin{array}{c}\text { Top homologous } \\
\text { species }\end{array}$ & References \\
\hline \multirow[t]{4}{*}{$\begin{array}{l}\text { MELO3C014657 } \\
(\text { CmPrx } 2-1)\end{array}$} & NP_001284470.1 & $\begin{array}{l}\text { Peroxidase 2-like } \\
\text { precursor }\end{array}$ & 91 & 0.0 & C. melo & $\begin{array}{l}\text { Keren-Keiserman et al. } \\
2004\end{array}$ \\
\hline & CAA76680.1 & Peroxidase & 74 & $3 e-167$ & Cucurbita pepo & Carpin et al. 1999 \\
\hline & KGN54102.1 & Peroxidase & 63 & 1e-129 & C. sativus & Ren et al. 2009 \\
\hline & AAM66044.1 & Peroxidase & 56 & $2 \mathrm{e}-125$ & Arabidopsis thaliana & $\begin{array}{l}\text { Haas et al. 2002; } \\
\text { Alexandrov et al. } 2006\end{array}$ \\
\hline \multirow[t]{4}{*}{$\begin{array}{l}\text { MELO3C014656 } \\
(\text { CmPrx } 2-2)\end{array}$} & NP_001284470.1 & $\begin{array}{l}\text { Peroxidase 2-like } \\
\text { precursor }\end{array}$ & 99 & 0.0 & C. melo & $\begin{array}{l}\text { Keren-Keiserman et al. } \\
2004\end{array}$ \\
\hline & CAA76680.1 & Peroxidase & 73 & $4 \mathrm{e}-164$ & C. реро & Carpin et al. 1999 \\
\hline & KGN54102.1 & Peroxidase & 62 & $4 \mathrm{e}-127$ & C. sativus & Ren et al. 2009 \\
\hline & AAM65211.1 & Peroxidase & 56 & le-121 & A. thaliana & $\begin{array}{l}\text { Haas et al. 2002; } \\
\text { Alexandrov et al. } 2006\end{array}$ \\
\hline \multirow[t]{2}{*}{$\begin{array}{l}\text { MELO3C002603 } \\
(C m G L S 1)\end{array}$} & $\begin{array}{l}\text { NP_567278.1 } \\
(\text { AtGSL1) }\end{array}$ & $\begin{array}{l}\text { Glucan } \\
\text { Synthase-Like } 1\end{array}$ & 70 & 0.0 & A. thaliana & Mayer et al. 1999 \\
\hline & $\begin{array}{l}\text { XP_007025627.1 } \\
\text { (TcGSL1-1) }\end{array}$ & $\begin{array}{l}\text { Glucan synthase-like } \\
1 \text { isoform } 1\end{array}$ & 75 & 0.0 & Theobroma cacao & Motamayor et al. 2013 \\
\hline
\end{tabular}

Biology Laboratories (EMBL) (http://smart.emblheidelberg.de/ smart/set_mode.cgi?Genomic=1) was used to identify the domains. Multiple alignments of three proteins were constructed with reference proteins using GeneDoc (www.psc.edu/biomed/genedoc) software (Nicholas and Nicholas 1997). Multiple genomic DNA sequence alignment was constructed among CmPrx2-1 and CmPrx2-2 with reference sequence using GeneDoc (www.psc.edu/biomed/genedoc) (Nicholas and Nicholas 1997). The number and arrangement of introns and exons were analyzed using Gene Structure Display Server (GSDS 2.0) by aligning the coding sequence (CDS) with the genomic sequences (Guo et al. 2007) (http://gsds. cbi.pku.edu.cn/). MEME software (Multiple Em for Motif Elicitation, V4.10.0) (http://meme-suite.org/tools/meme) was used to analyze the conserved motifs of the selected proteins along with the reference sequences (Bailey et al. 2006). The MEME search was set to identify maximum 10 motifs for each protein.

\section{Phylogenetic analysis}

We retrieved the Arabidopsis, cucumber and summer squash protein sequences homologous to three selected defense-related proteins of $C$. melo through NCBI blast search (http://www.ncbi.nlm.nih.gov/blast/). ClustalW software was used to align all protein sequences of CmPrx2-1, CmPrx2-2, and CmGLS1 from four different crop species including the reference protein sequences (Thompson et al. 1997). A phylogenetic tree was generated with MEGA6.06 using the Neighbor-Joining algorithm (Saitou and Nei 1987; Tamura et al. 2007). Two distinct clades of peroxidase, and glucan synthase were identified which were named according to reference protein. Bootstrap analysis with 1,000 replicates was conducted to evaluate the significance of the nodes.

\section{Plant materials}

In this study, we used $C$. melo SCNU1154 line that is susceptible against all identified races of PM fungus. Seeds of SCNU1154 line were soaked overnight to enhance germination and were sown in plastic pots containing sterilized soil mixture. Then seedlings were grown in a growth chamber at $22^{\circ} \mathrm{C}, 16: 8$ hours light/dark with a photon flux density of $140 \mu_{m o l m}{ }^{-2} \mathrm{~s}^{-1}$. The relative humidity was kept between $65 \%$ and $75 \%$. The selected plant organs of fresh roots, stems, leaves at three leaf 
stages, and flowers were harvested. The samples were snap frozen in liquid nitrogen and then kept at $-80^{\circ} \mathrm{C}$ for organ-specific expression analysis.

\section{Biotic stress treatments}

We initially cultured the seven races of $P$. xanthii viz., KPH19, KPH01, BN968, DH487, BN625, SN102, and $B N 103$, on detached leaves of SCNU1154 line in petri dishes containing fungal growth media (mixture of $5 \mathrm{~g}$ agar powder $+20 \mathrm{~g}$ D-Mannitol $+10 \mathrm{~g}$ saccharose in $1,000 \mathrm{ml}$ distilled water) in a growth chamber at $22^{\circ} \mathrm{C}$ with $16: 8$ hours day: night photoperiodic cycle and a photon flux density of $140 \mu \mathrm{molm}^{-2} \mathrm{~s}^{-1}$. Thereafter, we performed biotic stress treatments using all seven races to the adaxial part of 5th leaf (from ground level) of the six-week-old seedlings using the sterilized pencil brushes. The $80 \%$ relative humidity was maintained during the stress period. To conserve moisture, the inoculated plants were wrapped with polythene leaving perforations to exchange air until the development of typical symptoms. Similarly, control plants were also brushed with a sterilized pencil brush without any fungal inoculum. Sampling from the 5th leaf of both infected and non-infected plants was done at 18 days post inoculation. The harvested samples were immediately shifted to liquid nitrogen and then stored at $-80^{\circ} \mathrm{C}$ for RNA extraction.

\section{Phytohormone stress treatments}

We conducted two phytohormone stress treatments on seedlings with three true leaves. Exogenous application with $100 \mu \mathrm{M}$ solutions of SA, and MeJA was performed at the adaxial position of the seedlings. Then, we wrapped the treated plants by polyvinyl bags up to 48 hours, leaving perforations to exchange air. A non-treated plant was sampled just before the commencement of treatments and considered as 'control (0 hour)'. Sterile water sprayed to the plants instead of phytohormones was regarded as 'mock' samples. The treated leaf samples (1st and 2nd leaves) at 0 hour, 30 minutes, 1 hour, 3 hours, 6 hours, 12 hours, 24 hours, and 48 hours were harvested after all treatment imposition including mock treatments. The harvested leaf samples were snap frozen and then stored at $-80^{\circ} \mathrm{C}$ until RNA extraction.

\section{RNA extraction}

We isolated the total RNA from the different organs of melon plants, as well as from the control and all stress-treated samples using an RNeasy mini kit (Qiagen, Hilden, Germany). RNase-free DNase (Promega, Madision, WI, USA) treatment was performed to remove any contaminants of genomic DNA. The cDNA synthesis was subsequently done by using the Superscript ${ }^{\circledR}$ III FirstStrand synthesis kit (Invitrogen, Carlsbad, CA, USA) according to the manufacturer's instructions.

\section{Reverse transcription-polymerase chain reaction expression analysis}

Reverse transcription-polymerase chain reaction (RTPCR) was performed using EmeraldAmp ${ }^{\circledR}$ GT PCR Master Mix (Takara, Shiga, Japan). Specific primers were designed for all genes for RT-PCR and CmActin primers from C. melo (Gene Bank Acc. AY859055; Cheng et al. 2012) were used as control (Supplementary Table 1). PCR was carried out using $50 \mathrm{ng}$ of cDNA from the roots, leaves, stems or flowers of C. melo SCNU1154 line as template (1 $\mu 1)$, PCR master mix $(8 \mu \mathrm{l}), 20 \mathrm{pmol}$ forward and reverse primers $(2 \mu \mathrm{l})$, and double-distilled $\mathrm{H}_{2} \mathrm{O}(9 \mu \mathrm{l})$ were mixed to make a total volume of $20 \mu \mathrm{l}$ in $0.5 \mathrm{ml}$ PCR tubes. The samples were then subjected to the following conditions: pre-denaturation for $94^{\circ} \mathrm{C}$ for 5 minutes, followed by 30 and 35 cycled 3 -step amplification at $94^{\circ} \mathrm{C}$ for 30 seconds, $58^{\circ} \mathrm{C}$ for 30 seconds, $72^{\circ} \mathrm{C}$ for 45 seconds, and a final extension for 5 minutes at $72^{\circ} \mathrm{C}$ in a PCR thermal cycler (Takara).

\section{Quantitative PCR expression analysis}

Real-time quantitative PCR was carried out using $1 \mu \mathrm{l}$ of 50 ng cDNA with a $20-\mu 1$ reaction volume using $2 \times$ qPCRBIO SyGreen Mix Lo-Rox SYBR ${ }^{\circledR}$ Green Supermix with ROX (PCR Biosystems Ltd., London, UK). The primers used in RT-PCR were also used for real-time PCR (Supplementary Table 1). The conditions for real time PCR were as follows: pre-incubation for 5 minutes at $95^{\circ} \mathrm{C}$, followed by 3 -step amplifications at $95^{\circ} \mathrm{C}$ for 15 seconds, $58^{\circ} \mathrm{C}$ for 15 seconds, and $72^{\circ} \mathrm{C}$ for 20 seconds for 40 cycles. The melting temperature was at $95^{\circ} \mathrm{C}$ for 10 seconds, $65^{\circ} \mathrm{C}$ 
for 60 seconds, and $97^{\circ} \mathrm{C}$ for 1 second as a default setting. The fluorescence was recorded following the last step of each cycle, and three replications were counted for each sample. Amplification, detection, and data analysis were carried out using LightCycler96 (Roche, Mannheim, Germany). The relative gene expression was estimated on the basis of the $2^{-\Delta \Delta c t}$ method (Livak and Schmittgen 2001).

\section{RESULTS}

\section{Sequence analysis of peroxidase and glucan synthase-like genes}

We retrieved two peroxidase and one glucan synthase like genes from the 'Melonomics' database (https:// melonomics.net/). The deduced amino acid of the retrieved two peroxidase genes shared high similarity of 91 and $99 \%$, respectively with the reference melon peroxidase 2-like protein while the retrieved glucan synthase gene accounted high similarity between $70 \%$ and $75 \%$ respectively with the reference Arabidopsis and Theobroma glucan synthase 1-like protein (Table 1). Therefore, we named these genes as C. melo peroxidase 2-like isoforms 1, CmPrx2-1, C. melo peroxidase 2-like isoforms 2, CmPrx2-2, and C. melo glucan synthase 1-like, CmGLS1 (Table 1). In addition, CmPrx2-1 and CmPrx2-2 proteins also shared from $62 \%$ to $74 \%$ similarity with peroxidase protein of other plants (Table 1). The predicted sizes of CmPrx2-1, CmPrx2-2, and CmGLS1 proteins are 37.2, 37.1, and $204.8 \mathrm{kDa}$, respectively and predicted isoelectric points are 6.01, 5.69, and 9.08, respectively (Table 2).

Analysis of protein domain organization revealed that CmPrx2-1 and CmPrx2-2 proteins contained one short signal peptide in their $\mathrm{N}$-terminal, and one large peroxidase domains (Fig. 1A). The peroxidase domain of CmPrx2-1 and CmPrx2-2 proteins is highly conserved with the reference peroxidase protein from Arabidopsis, melon and summer squash (Fig. 1A). Conversely, CmGLS1 protein contained one FKS1_dom1 domain in their N-terminal, eight transmembrane domains and one glucan synthase domain (Fig. 1B). The glucan synthase domain of CmGLS1 protein is also highly conserved with the reference glucan synthase protein from Arabidopsis and

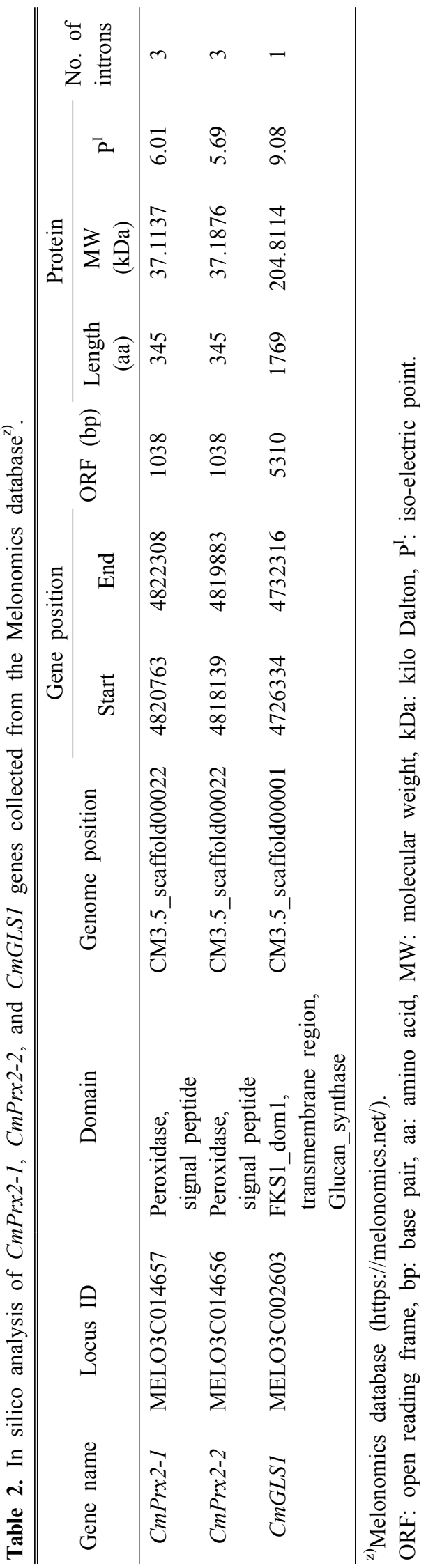




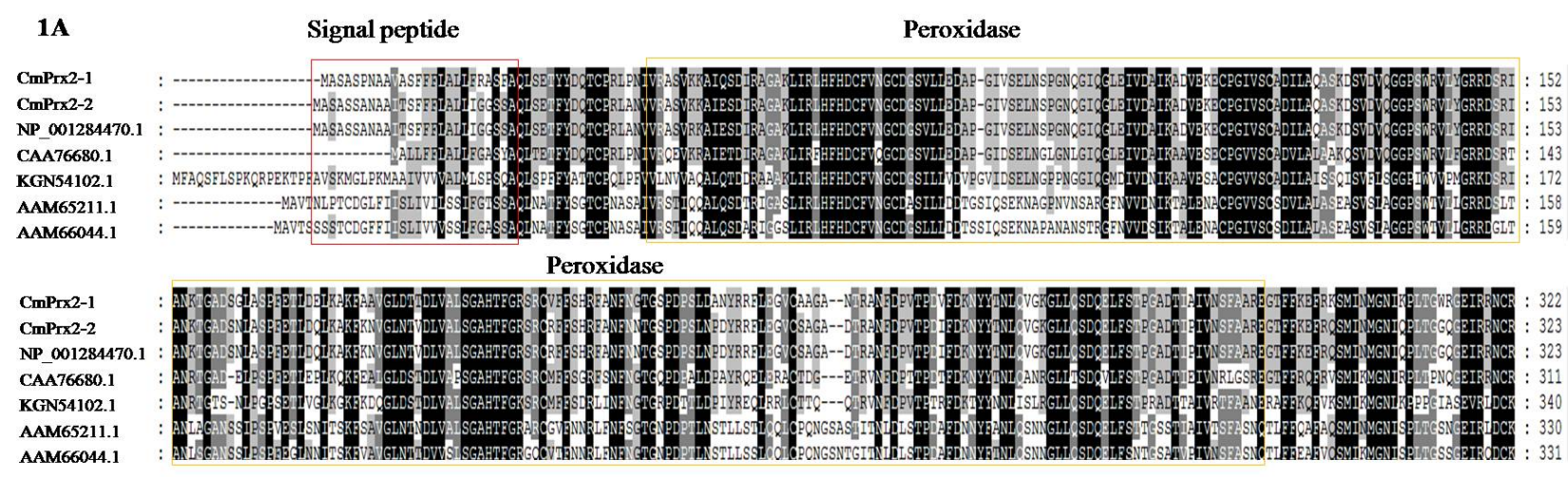

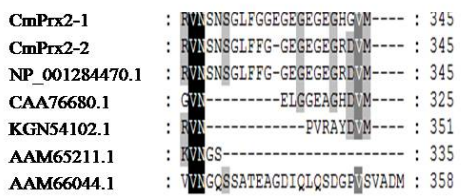

$1 \mathbf{B}$

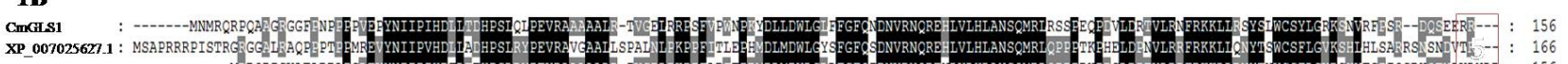

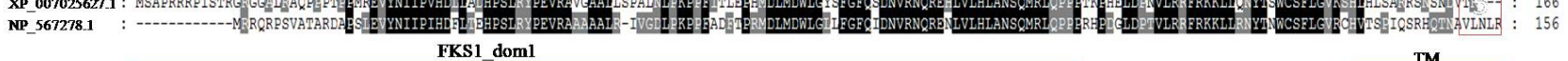
TM

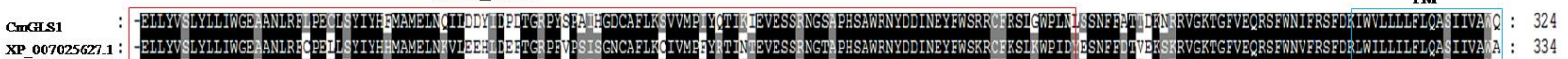

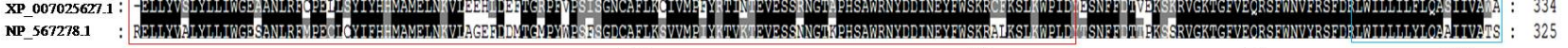

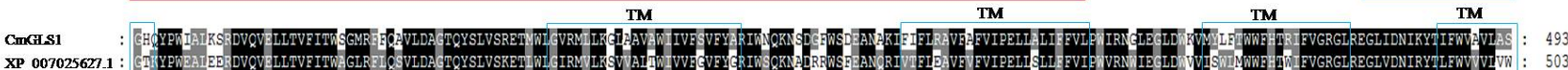

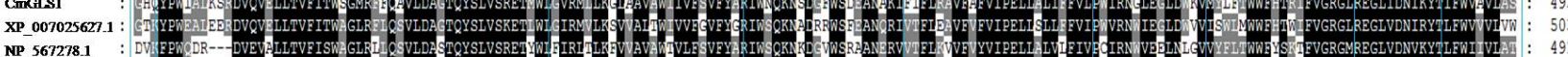

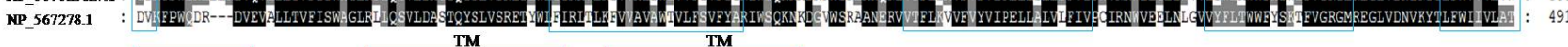

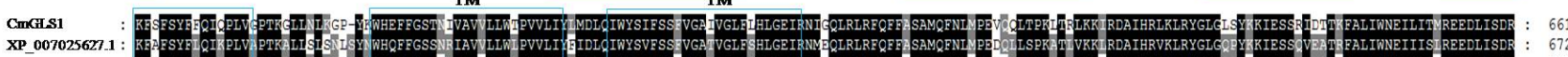

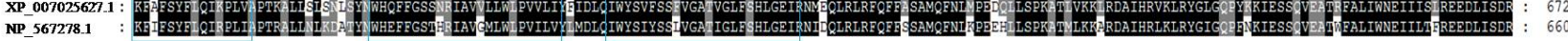

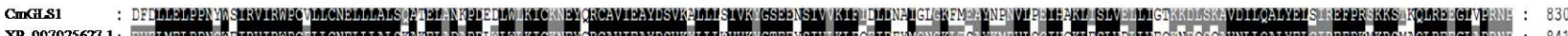

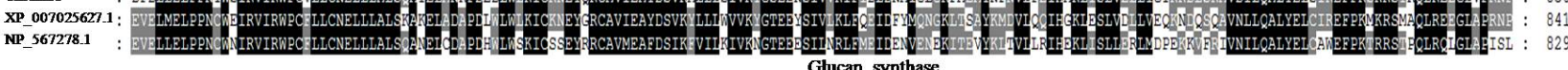
Doun

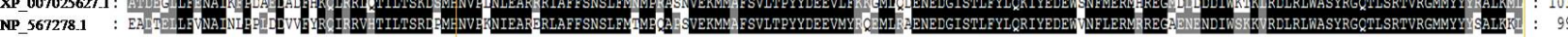

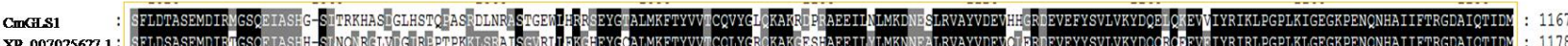
NP 567771 :

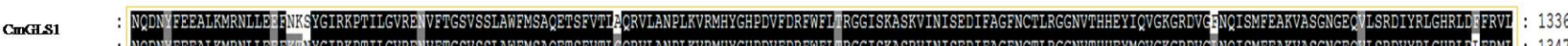

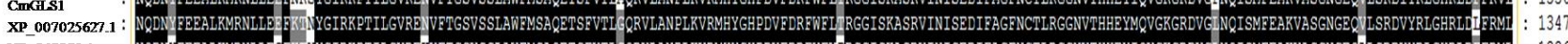

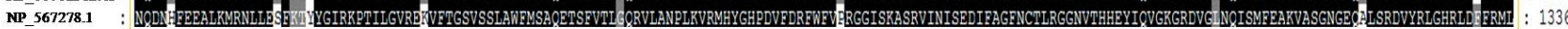

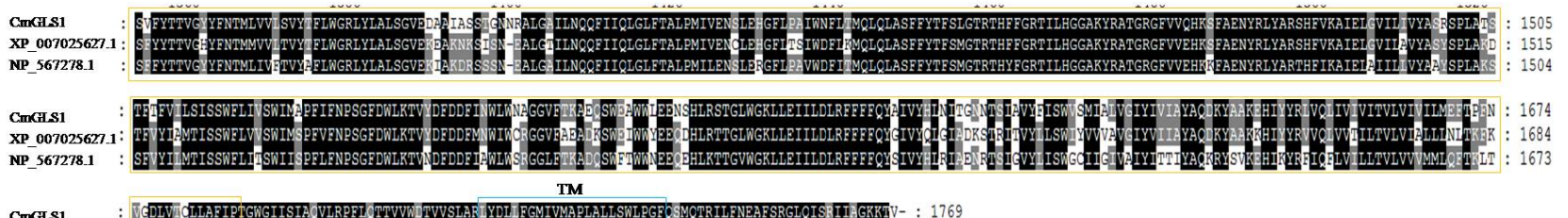

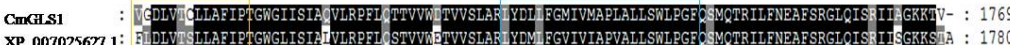

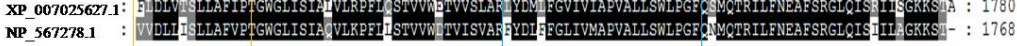

Fig. 1. Sequence alignment of Cucumis melo peroxidase and glucan synthase proteins. (A) Peroxidase, CmPrx2-1, MELO3C014657; CmPrx2-2, MELO3C014656 and (B) glucan synthase, CmGLS1, MELO3C002603 with other plant peroxidase (Arabidopsis, Arabidopsis thaliana, AAM65211.1 and AAM66044.1; Melon, $C$. melo, NP_001284470.1; Summer squash, Cucurbita pepo, CAA76680.1; Cucumber, C. sativus, KGN54102.1) and glucan snthase (Arabidopsis, A. thaliana, NP_567278.1; Theobroma, Theobroma cacao, XP_007025627.1) proteins. The alignment was generated by CLUSTALW using default parameters. (A) Red colored box represents signal peptide; orange colored box designates peroxidase domain. (B) Orange colored box represents glucan synthase domain; red colored box indicates FKS1_dom1 domain and blue colored boxes indicates different transmembrane domain (TM). 
Theobroma (Fig. 1B).

Furthermore, we performed multiple alignment among CmPrx2-1, CmPrx2-2 and two reference peroxidase 2-like genes (C. melo, ASM31304v1; C. sativus, ASM407v2) (Supplementary Fig. 1) and found that genomic sequence of CmPrx2-2 had a total of additional six adenine (A) both in intron and exon part (green colored box in Supplementary Fig. 1), while much nucleotide variation was observed in genomic sequence of $C m P r x 2-1$ compared to reference peroxidase 2-like genes (C. melo, ASM31304v1). Analysis of intron and exon distribution showed that $C m P r x 2-1$ and CmPrx2-2 gene displayed similar splicing pattern where CmGLS1 gene exhibited a quite different splicing pattern (Fig. 2A).

We observed that ten identical motifs were conserved in CmPrx2-1 and CmPrx2-2 proteins, ranging between 11 and 50 amino acids (Fig. 2B-I). Conserved motif 1, 2, 3, 4, $5,6,7$, and 8 were present in all peroxidase proteins examined (Fig. 2B-I). Motif 9 and 10 were absent in two peroxidase proteins from Arabidopsis (AAM65211.1 and
AAM66044.1), and motif 10 was absent in cucumber (KGN54102.1) (Fig. 2B-I). However, there were 10 conserved motifs present in all 3 glucan synthase proteins examined with 50 amino acids (Fig. 2B-II). Phylogenetic analysis showed that CmPrx2-1 and CmPrx2-2 proteins are distributed in peroxidase clade and CmGLS1 protein is in glucan synthase clade (Fig. 3).

\section{Organ-specific expression analysis}

The organ-specific RT-PCR expression pattern was much obvious at 35 cycles of amplification in contrast to 30 cycles (Fig. 4). The expression of $C m P r x 2-1, C m P r x 2-2$, and $C m G L S 1$ genes was noticed in all organs tested in $C$. melo SCNU1154 line and varied widely in terms of the level of expression except $\operatorname{CmPrx} 2-2$ gene which is not expressed in leaf tissue (Fig. 4).

\section{qPCR expression analysis under biotic stress} treatment

C. melo peroxidase 2-like isoform 1 (CmPrx2-1)

\section{$\mathbf{A}$}

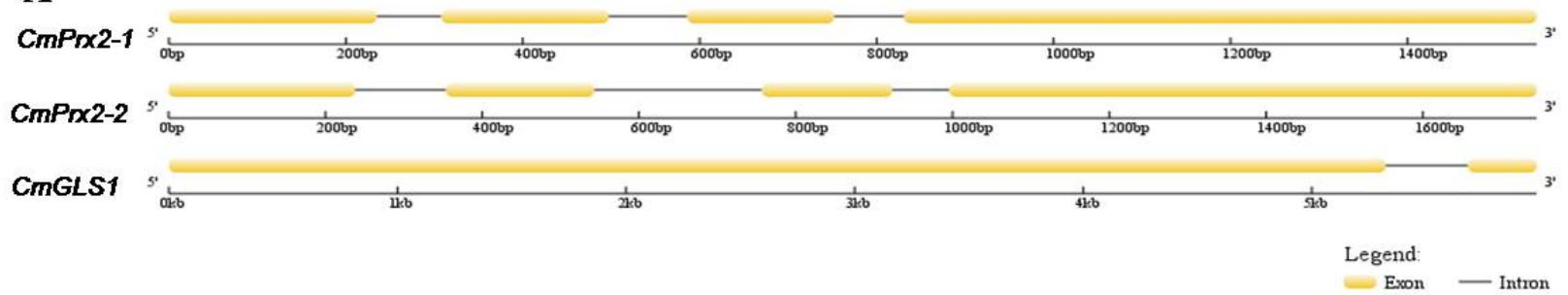

B-I

CmPrx2-1

CmPrx2-2

NP_001284470_1

CĀA76680_1

AAM652111

AAM66044

KGN54102.1

\section{B-II}

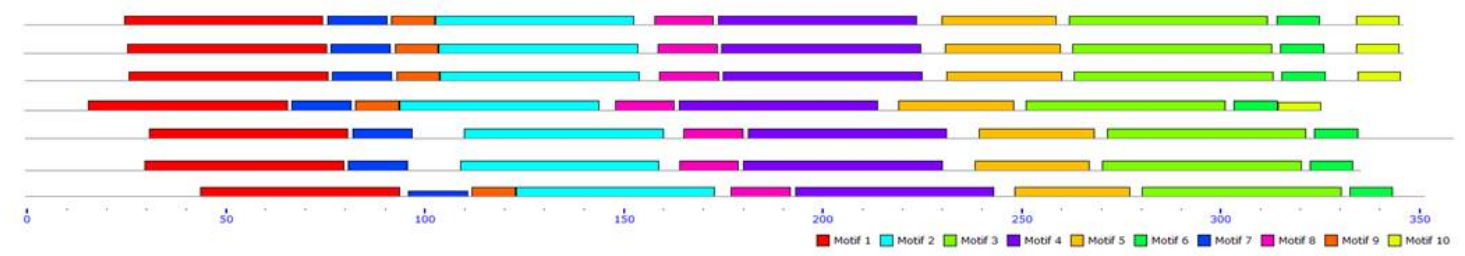

CmKHs1

NP_567278.1

XP 007025627

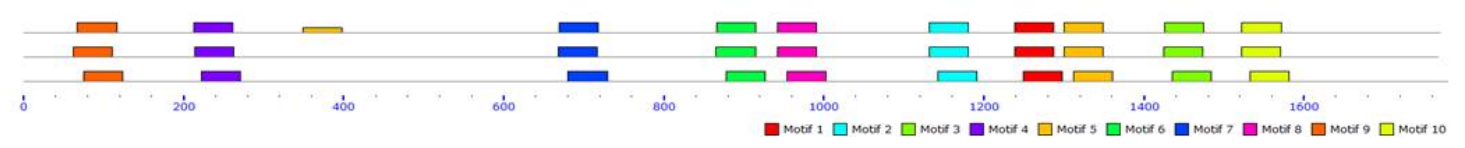

Fig. 2. (A) Schematic representation of intron-exon distribution of CmPrx2-1, CmPrx2-2, and CmGLS1 genes in Cucumis melo. Comparisons of motifs distribution of Fig. B-I. peroxidase and Fig. B-II. glucan synthase hormone related proteins in C. melo with other plant proteins, peroxidase (Arabidopsis, Arabidopsis thaliana, AAM65211.1 and AAM66044.1; Melon, C. melo, NP_001284470.1; Summer squash, Cucurbita pepo, CAA76680.1; Cucumber, C. sativus, KGN54102.1) and glucan synthase (Arabidopsis, A. thaliana, NP_567278.1; Theobroma, Theobroma cacao, XP_007025627.1). 


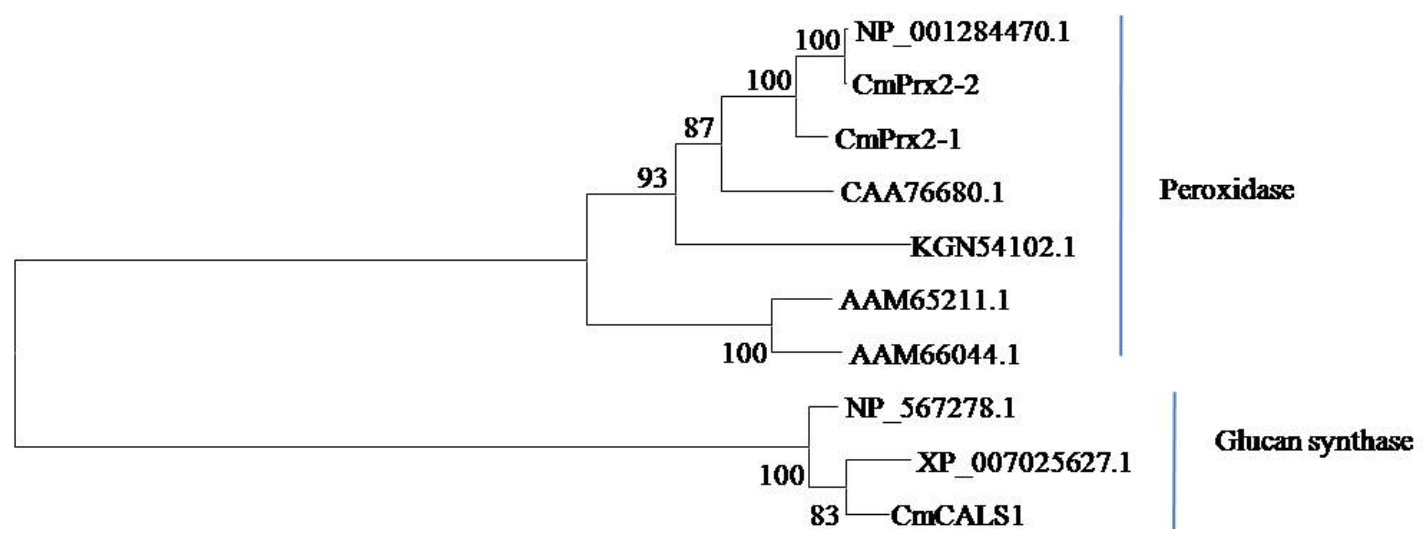

Fig. 3. Phylogenetic relationships of the deduced amino acid sequences of CmPrx2-1, CmPrx2-2 and CmGLS1 proteins (peroxidase, CmPrx2-1, MELO3C014657; CmPrx2-2, MELO3C014656 and glucan synthase, CmGLS1, MELO3C002603) with other plant peroxidase (Arabidopsis, Arabidopsis thaliana, AAM65211.1 and AAM66044.1; Melon, Cucumis melo, NP_001284470.1; Summer squash, Cucurbita pepo, CAA76680.1; Cucumber, C. sativus, KGN54102.1) and glucan synthase proteins (Arabidopsis, A. thaliana, NP_567278.1; Theobroma, Theobroma cacao, XP_007025627.1). The scale represents the frequency of amino acid substitutions between sequences as determined by the Poisson evolutionary distance method.

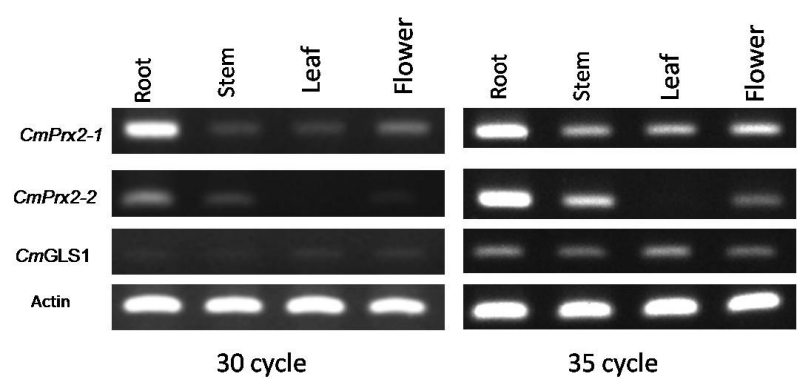

Fig. 4. Expression of CmPrx2-1, CmPrx2-2, and CmGLS1 in different organs of Cucumis melo. Reverse transcription- polymerase chain reaction (PCR) analysis of 3 genes is shown for in roots, stems, leaves, and flowers of $C$. melo. PCR amplification was recorded at both 30 and 35 cycles.

displayed race-specific expression against seven races of PM fungus $P$. xanthii after infection (Fig. 5). CmPrx2-1 showed the highest level of expression against KPH19 followed by $B N 968, K P H 01, B N 103, D H 487$, and exhibited comparatively lower level of expression against BN625 and SN102 races compared to control (Fig. 5). The approximate relative expression of $\mathrm{CmPrx2-1}$ gene varied between 1.2 and 2.2 fold against the up-regulated races (Fig. 5).

Conversely, C. melo peroxidase 2-like isoform 2 (CmPrx2-2) was up-regulated in response to all seven races of $P$. xanthii infection compared to control (Fig. 5). The maximum up-regulation was recorded against $\mathrm{KPHOI}$ followed by BN968, KPH19, DH487, BN103, BN625, and $S N 102$ races (Fig. 5). The approximate relative expression of $C m P r x 2-2$ gene varied between 8.0 and 30.0 fold against all seven up-regulated races (Fig. 5).

However, $C m G L S 1$ gene was down-regulated in response to six races of $P$. xanthii infection compared to control while this gene was almost inactive against $B N 625$ race (Fig. 5). The maximum down-regulation was observed against BN103 followed by BN968, SN102, DH487, KPH19, and KPHO1 races (Fig. 5).

\section{qPCR expression analysis after exogenous phytohormone treatments}

Furthermore, to explore the expression analysis of CmPrx2-1, CmPrx2-2, and CmGLS1 genes we exogenously sprayed the two defense signaling molecules viz. SA and MeJA in the current study. Under SA and MeJA treatment, two isoforms of peroxidase 2-like genes (CmPrx2-1 and CmPrx2-2) and one glucan synthase 1-like gene ( $C m G L S 1)$ were up-regulated compared to control (Fig. 6). Peroxidase 2-like isoform 1 (CmPrx2-1) showed maximum up-regulation of 84 fold and 17 fold at 6 hours after exogenous application of SA and MeJA, respectively and thereafter 


\section{CmPrx2-1}

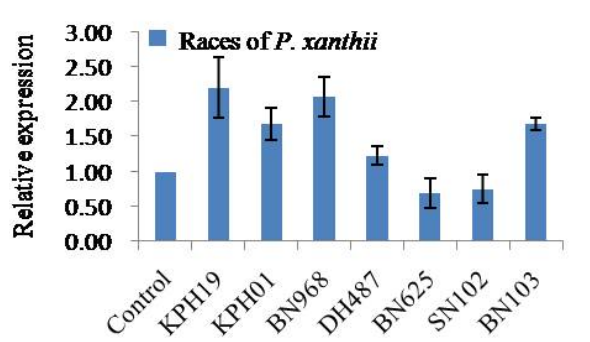

CmPrx2-2

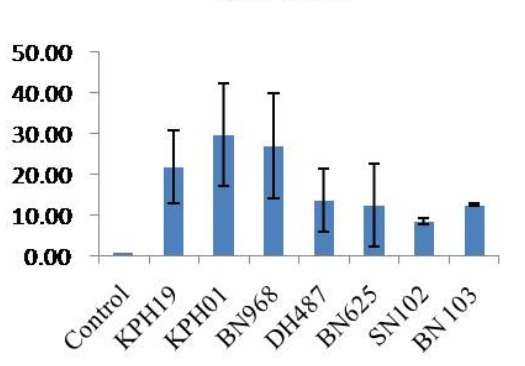

CmGLS1

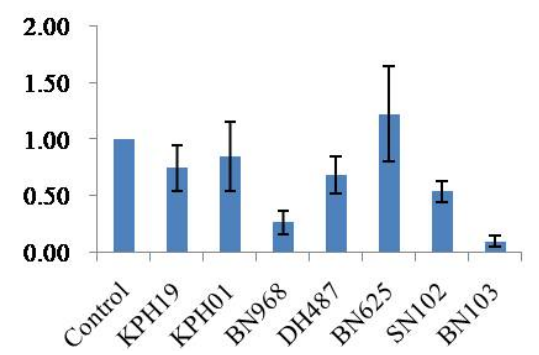

Fig. 5. Real-time quantitative polymerase chain reactionrelative expression analysis of CmPrx2-1, CmPrx2-2, and CmGLS1 genes after infection with seven races of powdery mildew fungus Podosphaera xanthii in Cucumis melo SCNU1154 plants. The error bars represent the standard error of the means of three independent replicates.
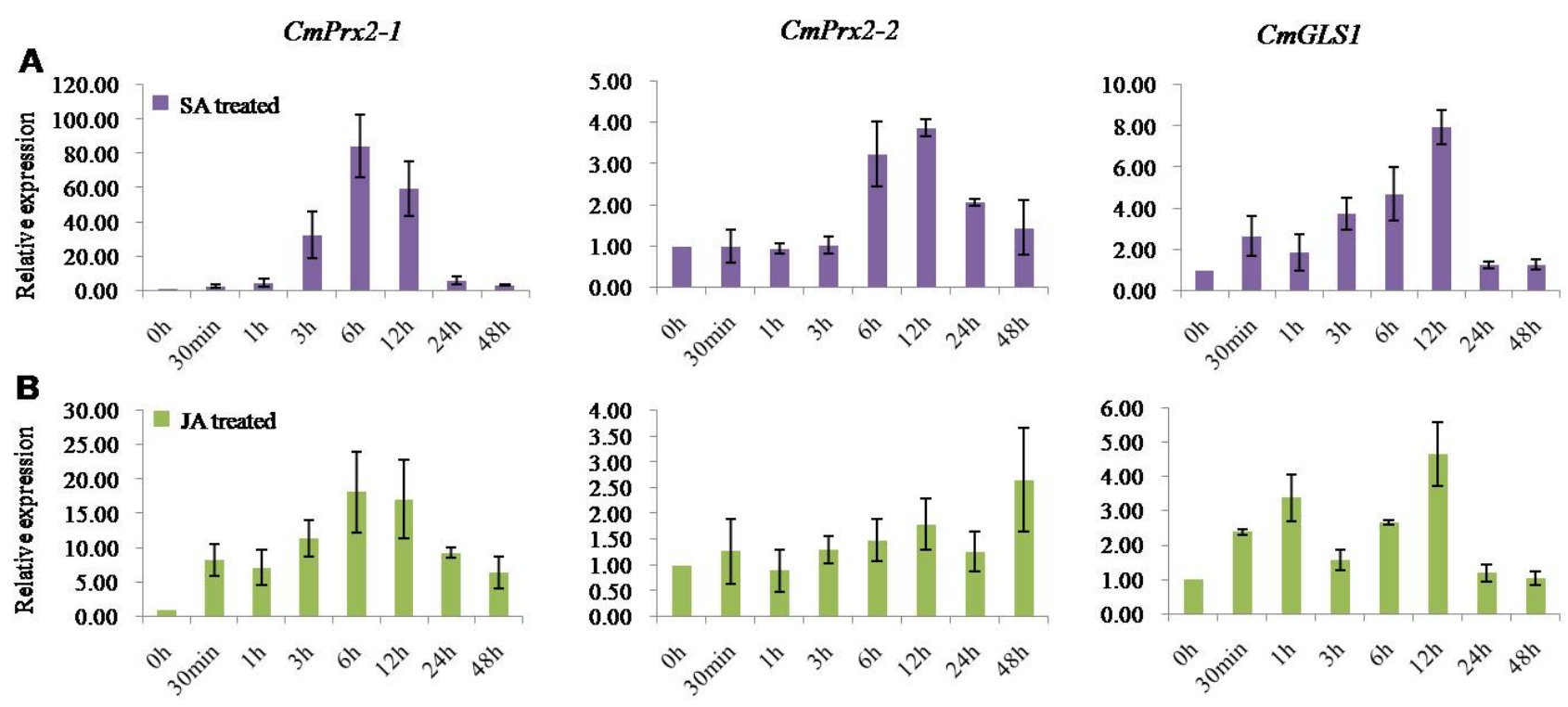

Fig. 6. Real-time quantitative polymerase chain reaction relative expression analysis of $C m P r x 2-1, C m P r x 2-2$, and $C m G L S 1$ genes after exogenous application of salicylic acid (SA) (A) and methyl jasmonate (MeJA) (B) in Cucumis melo SCNU1154 plants. The error bars represent the standard error of the means of three independent replicates.

declined upto the end of the treatment periods (Fig. 6). Similarly, peroxidase 2-like isoform 2 (CmPrx2-2) exhibited maximum up-regulations of 3.88 fold at 12 hours after SA treatment and 2.66 fold at 48 hours after MeJA treatment (Fig. 6). CmGLS1 genes displayed maximum up-regulation of nearly 8 fold and 4.8 fold at 12 hours after exogenous application of SA and MeJA, respectively (Fig. 6).

\section{DISCUSSION}

To explore the expression profiling of defense-related genes, two peroxidase 2-like genes viz. CmPrx2-1, CmPrx2-2, and one glucan synthase 1-like gene viz. CmGLS1 genes were retrieved from Melon Genome Database 'Melonomics' (https://melonomics.net/). Protein domain organization revealed that $\mathrm{CmPrx} 2-1$ and $\mathrm{CmPrx} 2-2$ isoforms contain characteristic features of signal peptide domains as of class III peroxidases (E.C.1.11.1.7) in their $\mathrm{N}$-termini (Fig. 1). Research data revealed that signal peptide targets the proteins into the secretory pathway via the endoplasmic reticulum (Penel 2000). The secreted plant peroxidases are very important to generate hydrogen peroxide $\left(\mathrm{H}_{2} \mathrm{O}_{2}\right)$ that takes part in oxidation reactions 
process needed for the cells (Penel 2000). Conversely, glucan synthase-like genes contain a typical glucan synthase domain that regulate callose synthases as plant defense mechanisms (Cui et al. 2001; Doblin et al. 2001; Hong et al. 2001; Østergaard et al. 2002). Apart from high homology of glucan synthase-like gene with yeast FK506 hypersensitivity $(F K S)$ genes, this gene is also speculated to be linked to (1,3)- $\beta$-D-glucan biosynthesis (Douglas et al. 1994; Cabib et al. 2001; Dijkgraaf et al. 2002). Moreover, $\beta$-1,3-glucan synthase (UDP-glucose; 1,3-b-D-glucan 3-b-D-glucosyltransferase; EC 2.4.1.34) is involved to catalyze the formation of a $\beta-1,3$-glucan polymer, a main component of the fungal cell wall (Shematek et al. 1980). Furthermore, although there is high similarity exists (99\%) between CmPrx2-2 and reference peroxidase 2-like protein (C. melo, NP_001284470.1), we speculate that CmPrx2-2 might be a distinct form of peroxidase 2-like gene in respect to reference one and might have a different function (Supplementary Fig. 1). This might be due to addition of adenine residues in $\mathrm{CmPrx2}$-2 genomic sequence (Supplementary Fig. 1).

The organ-specific expression analysis of defense related genes was done to select an appropriate organ for $\mathrm{qPCR}$ analysis (Fig. 3). Variable level of expression was observed in case of CmPrx2-1, CmPrx2-2, and CmGLS1 genes. This observation suggests that these three defense-related genes are differentially expressed in different organs and are involved in growth and developmental functions in melon.

CmPrx2-1 displayed race-specific expression against seven different races of PM fungus $P$. xanthii (Fig. 5). Previous results indicated that the higher the up-regulation of the peroxidase gene under PM fungus infection was associated with plant defense reaction against pathogen challenge (García-Gutiérrez et al. 2013). The race-specific up-regulation might be resulted in response to interaction between race-specific $\mathrm{R}$ genes in the host cell and a corresponding fungal Avr gene (Glazebrook 1999; Schulze-Lefert and Vogel 2000). In addition, the gene-for-gene interaction triggers defense reactions, such as the HR, to restrict pathogen growth and reproduction (Hammond-Kosack and Jones 1996). In plant-microbe interaction, PM fungus might generate microbial effectors that could interact only with host $\mathrm{R}$ genes for hyper- sensitive reactions resulting PM resistance. However, the lack of resistant genes probably brings to a compatible disease reaction (Panstruga 2003). This indicates that microbial effectors protein generated by the different races of $P$. xanthii was variable and that different peroxidase isoforms and glucan synthase like genes were essential for their effective recognition.

Conversely, $\mathrm{CmPrx2-2}$ was up-regulated in response to all seven races of $P$. xanthii compared to control (Fig. 5). Although CmPrx2-1 and CmPrx2-2 genes contained the conserved signal peptide and peroxidase domain, their expression pattern and level varied noticeably against different races of PM fungus (Fig. 5). Research reports revealed that despite of high homology (from 28\% to $100 \%$ ) between two peroxidase proteins, the particular isoform function is quite different in defense responses against pathogen challenge (Penel et al. 1992; Hiraga et al. 2001). Furthermore, plant defensive peroxidases, induced by SA and JA signaling pathway, are involved to generate lignin and hydrogen peroxide as a HR upon pathogen challenge and thereby play roles in plant disease resistance mechanisms (Avdiushko et al. 1993; Niranjan Raj et al. 2012). Therefore, we speculate that highly induced CmPrx2-1 and CmPrx2-2 genes might be related to plant disease resistance against PM fungus $P$. xanthii in C. melo L.

CmGLS1 gene was down-regulated in response to six races of $P$. xanthii compared to controls while this gene was almost inactive against BN625 race (Fig. 5). Previous reports showed that GSL5/Powdery Mildew Resistant 4 (PMR4)/CalS12 generates callose as a defense response in sporophytic tissue after pathogen challenge or wounding treatment in plants. Conversely, due to loss of function, mutant of $g s / 5 / \mathrm{pmr} 4 / \mathrm{cals} 12$ was unable to generate callose at papillae (Jacobs et al. 2003; Nishimura et al. 2003; Dong et al. 2008). However, apart from callose synthesis, plant evolved multiple defense mechanisms against pathogen challenge (Jacobs et al. 2003; Nishimura et al. 2003; Dong et al. 2008). Interestingly, callose generated upon pathogen challenge is involved negatively to controls the SA signaling pathway of plants (Nishimura et al. 2003). Conversely, the powdery mildew resistant 4 (pmr4) mutant in Arabidopsis reduce callose deposition after fungal penetration and could activate SA defense signaling and 
thereby increased resistance to pathogen (Nishimura et al. 2003). Therefore, we speculate that our CmGLS1 gene might be a mutant as the expression of this gene is down-regulated against almost all races of PM fungus after infection and might function in plant disease resistance response through this pathway.

Moreover, we also investigated the expression behavior of CmPrx2-1, CmPrx2-2, and CmGLS1 genes under exogenous application of two defense signaling molecules viz. SA and MeJA. Importantly, we observed that all of three genes viz. CmPrx 2-1, CmPrx2-2, and CmGLS1 were highly induced by SA treatment over MeJA (Fig. 6) (Glazebrook 2005). Some notable reports revealed that plant defense responsive peroxidase genes are induced by both SA and jasmonate (JA) signaling pathways (Durrant and Dong 2004; van Loon et al. 2006; Pieterse et al. 2009). Likewise, plant defense genes against biotrophic pathogens were also highly induced by application of exogenous SA in Arabidopsis (Thomma et al. 2001). Signaling molecules MeJA plays a crucial role in plant defense, programmed cell death and leaf senescence (Reinbothe et al. 2009). Taken together, we propose that apart from growth and developmental roles, three defense responsive genes studied herein might function more effectively through SA-signal mediated pathway over MeJA against biotrophic PM fungus P. xanthii. However, this speculation needs further validation through simultaneous application of exogenous phytohormones and $P$. xanthii fungal inocula. The results of this study would be valuable resources for further functional characterization and development of PM stress resistant variety of C. melo L.

\section{ACKNOWLEDGEMENTS}

This research work was done by the funding of Export Promotion Technology Development Program (Grant No. 312065-05-4-HD030) and Golden Seed Project (Center for Horticultural Seed Development, No. 213003-04-4-SB110) of the Ministry of Agriculture, Food and Rural Affairs (MAFRA), Republic of Korea.

\section{REFERENCES}

Alexandrov NN, Troukhan ME, Brover VV, Tatarinova T, Flavell RB, Feldmann KA. 2006. Features of Arabidopsis genes and genome discovered using full-length cDNAs. Plant Mol. Biol. 60: 69-85.

Avdiushko SA, Ye XS, Kuc J. 1993. Detection of several enzymatic activities in leaf prints cucumber plants. Physiol. Mol. Plant. Pathol. 42: 441-454.

Bailey TL, Williams N, Misleh C, Li WW. 2006. MEME: discovering and analyzing DNA and protein sequence motifs. Nucleic Acids Res. 34: 369-373.

Bardin M, Dogimont C, Nicot P, Pitrat M. 1999. Genetic analysis of resistance of melon line PI 124112 to Sphaerotheca fuliginea and Erysiphe cichoracearum studied in recombinant inbred lines. Acta Hort. 492: 163-168.

Cabib E, Roh DH, Schmidt M, Crotti LB, Varma A. 2001. The yeast cell wall and septum as paradigms of cell growth and morphogenesis. J. Biol. Chem. 276: 19679-19682.

Carpin S, Crèvecoeur M, Greppin H, Penel C. 1999. Molecular cloning and tissue-specific expression of an anionic peroxidase in zucchini. Plant Physiol. 120: 799-810.

Cheng H, Kun W, Liu D, Su Y, He Q. 2012. Molecular cloning and expression analysis of CmMlol in melon. Mol. Biol. Rep. 39: 1903-1907.

Cohen Y, Eyal H, Thomas CE. 1984. Stabilizing resistance in Cucumis melo against downy and powdery mildews in Israel and the USA (abstract). Phytopathology 74: 829.

Cui X, Shin H, Song C, Laosinchai W, Amano Y, Brown RM Jr. 2001. A putative plant homolog of the yeast $\beta$-1,3-glucan synthase subunit FKS1 from cotton (Gossypium hirsutum L.) fibers. Planta 213: 223-230.

Dangl JL, Jones JD. 2001. Plant pathogens and integrated defence responses to infection. Nature 411: 826-833.

Dijkgraaf GJ, Abe M, Ohya Y, Bussey H. 2002. Mutations in Fkslp affect the cell wall content of $\beta-1,3-$ and $\beta-1,6-$ glucan in Saccharomyces cerevisiae. Yeast 19: 671-690.

Doblin MS, De Melis L, Newbigin E, Bacic A, Read SM. 2001. Pollen tubes of Nicotiana alata express two genes from different $\beta$-glucan synthase families. Plant Physiol. 125: 2040-2052. 
Dong X, Hong Z, Chatterjee J, Kim S, Verma DP. 2008. Expression of callose synthase genes and its connection with Npr1 signaling pathway during pathogen infection. Planta 229: 87-98.

Douglas CM, Foor F, Marrinan JA, Morin N, Nielsen JB, Dahl AM, et al. 1994. The saccharomyces cerevisiae FKS1 (ETG1) gene encodes an integral membrane protein which is a subunit of 1,3-beta-D-glucan synthase. Proc. Natl. Acad. Sci. U.S.A. 91: 12907-12911.

Durrant WE, Dong X. 2004. Systemic acquired resistance. Annu. Rev. Phytopathol. 42: 185-209.

Ellinger D, Naumann M, Falter C, Zwikowics C, Jamrow T, Manisseri C, et al. 2013. Elevated early callose deposition results in complete penetration resistance to powdery mildew in Arabidopsis. Plant Physiol. 161: 1433-1444.

Epinat C, Pitrat M, Bertrand F. 1993. Genetic analysis of resistance of five melon lines to powdery mildews. Euphytica 65: 135-144.

García-Gutiérrez L, Zeriouh H, Romero D, Cubero J, de Vicente A, Pérez-García A. 2013. The antagonistic strain Bacillus subtilis UMAF6639 also confers protection to melon plants against cucurbit powdery mildew by activation of jasmonate- and salicylic acid-dependent defence responses. Microb. Biotechnol. 6: 264-274.

Glazebrook J. 1999. Genes controlling expression of defense responses in Arabidopsis. Curr. Opin. Plant Biol. 2: 280-286.

Glazebrook J. 2005. Contrasting mechanisms of defense against biotrophic and necrotrophic pathogens. Annu. Rev. Phytopathol. 43: 205-227.

Guo AY, Zhu QH, Chen X, Luo JC. 2007. GSDS: a gene structure display server. Yi Chuan 29: 1023-1026.

Haas BJ, Volfovsky N, Town CD, Troukhan M, Alexandrov N, Feldmann KA, et al. 2002. Full-length messenger RNA sequences greatly improve genome annotation. Genome Biol. 3: RESEARCH0029.

Hammond-Kosack KE, Jones JD. 1996. Resistance gene-dependent plant defense responses. Plant Cell 8: 1773-1791.

Hewitt HG. 1998. Fungicides in crop protection. CABI Publishing, Wallingford, UK.

Hiraga S, Sasaki K, Ito H, Ohashi Y, Matsui H. 2001. A large family of class III plant peroxidases. Plant Cell Physiol. 42: 462-468.
Hollomon DW, Wheeler IE. 2002. Controlling powdery mildews with chemistry. APS Press, St Paul, MN. p.249-255.

Hong Z, Delauney AJ, Verma DP. 2001. A cell plate-specific callose synthase and its interaction with phragmoplastin. Plant Cell 13: 755-768.

Hosoya K, Kuzuya M, Murakami T, Kato K, Narisawa K, Ezura H. 2000. Impact of resistant melon cultivars on Sphaerotheca fuliginea. Plant Breed. 119: 286-288.

Hosoya K, Narisawa K, Pitrat M, Ezura H. 1999. Race identification in powdery mildew (Sphaerotheca fuliginea) on melon (Cucumis melo L.) in Japan. Plant Breed. 118: 259-262.

Huibers RP, Loonen AE, Gao D, Van den Ackerveken G, Visser RG, Bai Y. 2013. Powdery mildew resistance in tomato by impairment of SIPMR4 and SIDMR1. PLoS ONE 8: e67467.

Jacobs AK, Lipka V, Burton RA, Panstruga R, Strizhov N, Schulze-Lefert P, et al. 2003. An Arabidopsis callose synthase, GSL5, is required for wound and papillary callose formation. Plant Cell 15: 2503-2513.

Jarvis WR, Gubler WD, Grove GG. 2002. Epidemiology of powdery mildews in agricultural pathosystems, p.169-199. In: R. R. Bélanger, W. R. Bushnell, A. J. Dik, T. L. W. Carver (ed.). The powdery mildews: a comprehensive treatise. APS Press, St. Paul, MN.

Keren-Keiserman A, Tanami Z, Shoseyov O, Ginzberg I. 2004. Peroxidase activity associated with suberization processes of the muskmelon (Cucumis melo) rind. Physiol. Plant 121: 141-148.

Kř́sstková E, Leveda A, Sedláková B. 2004. Virulence of Czech cucurbit powdery mildew isolates on Cucumis melo genotypes MR-1 and PI 124112. Sci. Hortic. 99: 257-265.

Livak KJ, Schmittgen TD. 2001. Analysis of relative gene expression data using real-time quantitative PCR and the $2^{-\triangle \triangle C T}$ method. Methods 25: 402-408.

Mayer K, Schüller C, Wambutt R, Murphy G, Volckaert G, Pohl T, et al. 1999. Sequence and analysis of chromosome 4 of the plant Arabidopsis thaliana. Nature 402: 769-777.

Motamayor JC, Mockaitis K, Schmutz J, Haiminen N, Livingstone D, Cornejo O, et al. 2013. The genome sequence of the most widely cultivated cacao type and its use to identify candidate genes regulating pod color. 
Genome Biol. 14: r53. doi: 10.1186/gb-2013-14-6-r53.

McCreight J, Pitrat M, Thomas CE, Kishaba AN, Bohn GW. 1987. Powdery mildew resistance genes in muskmelon. J. Am. Soc. Hortic. Sci. 112: 156-160.

Nicholas KB, Nicholas HBJ. 1997. GeneDoc: a tool for editing and annotating multiple sequence alignments [Internet]. [cited 2016 Feb 22]. Available from: http://www.citeulike.org/user/gwallau/article/6113940.

Niranjan Raj S, Lavanya SN, Amruthesh KN, Niranjana SR, Reddy MS, Shetty HS. 2012. Histo-chemical changes induced by PGPR during induction of resistance in pearl millet against downy mildew disease. Biol. Control 60: 90-102.

Nishimura MT, Stein M, Hou BH, Vogel JP, Edwards H, Somerville SC. 2003. Loss of a callose synthase results in salicylic acid-dependent disease resistance. Science 301: 969-972.

Østergaard L, Petersen M, Mattsson O, Mundy J. 2002. An Arabidopsis callose synthase. Plant Mol. Biol. 49: 559-566.

Panstruga R. 2003. Establishing compatibility between plants and obligate biotrophic pathogens. Curr. Opin. Plant Biol. 6: 320-326.

Penel C, Gaspar T, Greppin H. 1992. Plant peroxidases news letter. University of Geneva, Geneva, Switzerland.

Penel C. 2000. The peroxidase system in higher plants. In: H. Greppin, C. Penel, W. J. Broughton, R. Strasser (ed.). Integrated plant systems, p.359-367. University of Geneva, Geneva, Switzerland.

Perchepied L, Bardin M, Dogimont C, Pitrat M. 2005. Relationship between Loci conferring downy mildew and powdery mildew resistance in melon assessed by quantitative trait Loci mapping. Phytopathology 95: 556-565.

Pieterse CM, León-Reyes A, Van der Ent S, Van Wees SC. 2009. Networking by small-molecule hormones in plant immunity. Nat. Chem. Biol. 5: 308-316.

Reinbothe C, Springer A, Samol I, Reinbothe S. 2009. Plant oxylipins: role of jasmonic acid during programmed cell death, defence and leaf senescence. FEBS J. 276: 4666-4681.
Ren Y, Zhang Z, Liu J, Staub JE, Han Y, Cheng Z, et al. 2009. An integrated genetic and cytogenetic map of the cucumber genome. PLoS One 4: e5795.

Saitou N, Nei M. 1987. The neighbor-joining method: a new method for reconstructing phylogenetic trees. Mol. Biol. Evol. 4: 406-425.

Schulze-Lefert P, Vogel J. 2000. Closing the ranks to attack by powdery mildew. Trends Plant Sci. 5: 343-348.

Shematek EM, Braatz JA, Cabib E. 1980. Biosynthesis of yeast cell wall. I. Preparation and properties of beta-(1 leads to 3) glucan synthetase. J. Biol. Chem. 255: 888-894.

Sowell G Jr. 1982. Population shift of Sphaerotheca fuliginea on musk melon. J. Am. Soc. Hortic. Sci. 112: 156-160

Stone BA, Clarke AE. 1992. Chemistry and biology of (1-3)- $\beta$-glucans. La Trobe University Press, Victoria, Australia.

Tamura K, Dudley J, Nei M, Kumar S. 2007. MEGA4: molecular evolutionary genetics analysis (MEGA) software version 4.0. Mol. Biol. Evol. 24: 1596-1599.

Thomas CE, Kishaba AN, McCreight JD, Nugent PE. 1984. The importance of monitoring races of powdery mildew on muskmelon. Rep. Cucurbit Genet. Coop. 7: 58-59.

Thomma BP, Penninckx IA, Broekaert WF, Cammue BP. 2001. The complexity of disease signaling in Arabidopsis. Curr. Opin. Immunol. 13: 63-68.

Thompson JD, Gibson TJ, Plewniak F, Jeanmougin F, Higgins DG. 1997. The CLUSTAL_X windows interface: flexible strategies for multiple sequence alignment aided by quality analysis tools. Nucleic Acids Res. 25: 4876-4882.

van Loon LC, Rep M, Pieterse CM. 2006. Significance of inducible defense-related proteins in infected plants. Annu. Rev. Phytopathol. 44: 135-162.

Veronese P, Ruiz MT, Coca MA, Hernandez-Lopez A, Lee H, Ibeas JI, et al. 2003. In defense against pathogens. Both plant sentinels and foot soldiers need to know the enemy. Plant Physiol. 131: 1580-1590.

Vogel J, Somerville S. 2000. Isolation and characterization of powdery mildew-resistant Arabidopsis mutants. Proc. Natl. Acad. Sci. U.S.A. 97: 1897-1902. 